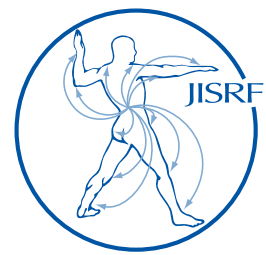

\title{
Our Experience with Short Stem Hip Replacement Surgery
}

Rastogi $S^{1}$, Marya $S^{1}$

\section{Abstract}

Context: A short anatomical metaphyseal femoral stem is a desirable hip implant for bone and soft tissue preserving hip replacing surgery in young active patients. Physiological loading of the proximal femur prevents stress shielding and preserves bone stock of the femur in the long run. Thus it is an ideal hip implant suited for conservative hip surgeries in young adults with arthritic hips.

Materials and Methods: 50 Proxima hip replacements were performed on 41 patients with a mean age of 45 over a 3-year period (between July 2006 and September 2009). Diagnosis of hip pathologies varied from osteoarthritis secondary to avascular necrosis, rheumatoid arthritis, post-tubercular arthritis to dysplastic hips. 9 of these patients had symptomatic bilateral hip involvement and underwent bilateral hip replacement in a single sitting. All patient had a Proxima metaphyseal stem implantation with either a large diameter metal on metal or pinnacle articulation. Clinical and radiological evaluation was done at 3 months, 6 months, 1 year and then yearly

Statiscal Analysis Used: VAS and Harris hip score formed the basis of evaluation

Results: These patients were followed up for a mean period of 49 months (Range 36-72 months). The average incision size was $14.38 \mathrm{~cm}(10-18 \mathrm{~cm})$ and blood loss was $269 \mathrm{ml}(175-450 \mathrm{ml})$. There was no peri-operative mortality or serious morbidity in any patients. One patient had an intraoperative lateral cortex crack that required only delayed rehabilitation. Five of the 41 patients $(12.1 \%)$ had complications with three recovering completely and one requiring revision of femoral stem for aseptic loosening. One patient was lost in follow-up. Harris hip score improved from 52 to 89.3 at last follow-up. Overall 95.1\% (39/41) patients had an excellent outcome at last follow-up.

Conclusion: We conclude that Proxima metaphyseal stem provided clinically and radiologically stable fixation through snug fit initially followed by bone in-growth and was ideally suited to satisfy the requirements of a conservative hip implant. Unfortunately, due to unknown reasons, the implant has been recently withdrawn from the market by DePuy and is no longer available for use.

Key Message: Conservative hip stems that preserve bone and soft tissue at the time of surgery, prevent

1 Dr. Sumeet Rastogi MBBS, DNB (Ortho), Dr. S K S Marya, MBBS, MS, DNB (Ortho)

Max Institute Of Musculoskeletal Sciences

No 1, Press Enclave Road, Saket, New Delhi, India

(Direct reprint requests to Sumeet Rastogi)
(C) 2016 Rastogi, Marya. All rights reserved.

Authors retain copyright and grant the journal right of first publication with the work. Reconstructive Review follows the Creative Commons Attribution-NonCommercial CC BY-NC. This license allows anyone to download works, build upon the material, and share them with others for non-commercial purposes as long as they credit the senior author, Reconstructive Review, and the Joint Implant Surgery \& Research Foundation (JISRF). An example credit would be: "Courtesy of (senior author's name), Reconstructive Review, JISRF, Chagrin Falls, Ohio". 
femoral stress shielding by circumferential loading, promote positive bone remodeling and help to make revision surgeries easier are ideal suited as hip implants for young active adults with end stage hip disease requiring hip replacement surgery.

Keywords: total hip replacement, uncemented, conservative, metaphyseal stems, Proxima.

Level of Evidence: AAOS Therapeutic Level IV

\section{Introduction}

Over the last two decades, the profile of the patient requiring hip replacement surgery has changed dramatically. Increasingly, more young and active patients with end stage hip disease are seeking hip replacement surgery. This change in the demographic profile of the patient has put an increased demand on the orthopaedic surgeons to conduct bone preserving surgeries especially keeping in mind the higher incidence of expected revision surgery in this age group. They realize that implants need to be designed so that they not only conserve bone and soft tissue but also are able to withstand the vigorous and demanding lifestyle of this age group.

Surgeons have largely opened up to the idea of uncemented hips. Substantial progress has been made in this area but a number of limitations remain, particularly with respect to bone preservation, stress shielding, thigh pain and revision surgery.

Anatomical metaphyseal stems are ideally poised to address these shortcomings. Bone and soft tissues sparing in approach, they promote more physiological loading of the proximal femur thus preserving bone strength and preventing stress shielding. Active bone ingrowth into the structured surface of stem provides both early and sustained bony fixation.

Research has been directed towards creating a modern femoral implant that is anatomical in shape, preserves healthy femoral bone during implantation, loads the neck and metaphyses in a near physiological manner and creates a biomechanically favorable offset while minimizing soft tissue handling.

\section{Material And Methods}

50 Proxima hip replacements were performed on 41 patients by the senior author between July 2006 and September 2009. This group included 25 males and 16 females. The average age of the patients at the time of surgery was 45 years (range 35 years to 55 years).
The diagnosis in 30 patients was osteoarthritis secondary to avascular necrosis, three patients had post-traumatic arthritis, three ankylosing spondylitis, three rheumatoid arthritis, one post tubercular arthritis and one had osteoarthritis secondary to a dysplastic hip. Out of the total of 41 patients, nine patients had bilateral hip involvement that was symptomatic and underwent bilateral hip replacement in the same sitting. All the patients were ambulatory when they presented for surgery. They were walking unaided or with support (cane or walker). A few of the patients had comorbidities such as HT, DM, CAD and CKD (14 out of 41).

All the patients were followed up until September 2012 , the average duration of follow-up being 49 months (range 36- 72 months) with minimum duration of follow-up of 3 years.

\section{General Measurements:}

The Harris hip score and VAS (Visual analogue score) were used to assess clinical outcome.

\section{Evaluation:}

All patients were subject to pre and post-operative clinical and radiological evaluation. This was done before and immediately after surgery, at 6 weeks, at 3 months, 6 months, 12 months and yearly interval thereafter.

\section{Clinical evaluation:}

General demographic data such as age, height and weight was noted. Additional information about the diagnosis, condition of the joint, movements, shortening and co-morbid conditions was recorded. Baseline Harris hip and VAS was also recorded.

The surgical approach, average surgical time, blood loss, details of any intra operative or peri-operative complications, incision length and implant sizes were recorded.

\section{Radiological evaluation:}

$\mathrm{X}$ rays of the affected hips were done at each checkup. At each point standard AP \& Lateral radiographs of the affected hip were taken. The femur was evaluated for signs of radiolucencies, osteolysis, subsidence, stem migration, stress shielding, bone remodeling and heterotrophic ossification. Similarly, the acetabular component was evaluated for radiolucencies, areas of osteolysis and migration/ protrusio.

\section{Surgical technique:}

Per-operatively, with the patient in a lateral position, the hip joint was exposed either through a posterior-lateral approach or a modified anterior-lateral approach. Af- 
CHART 1 - patient details

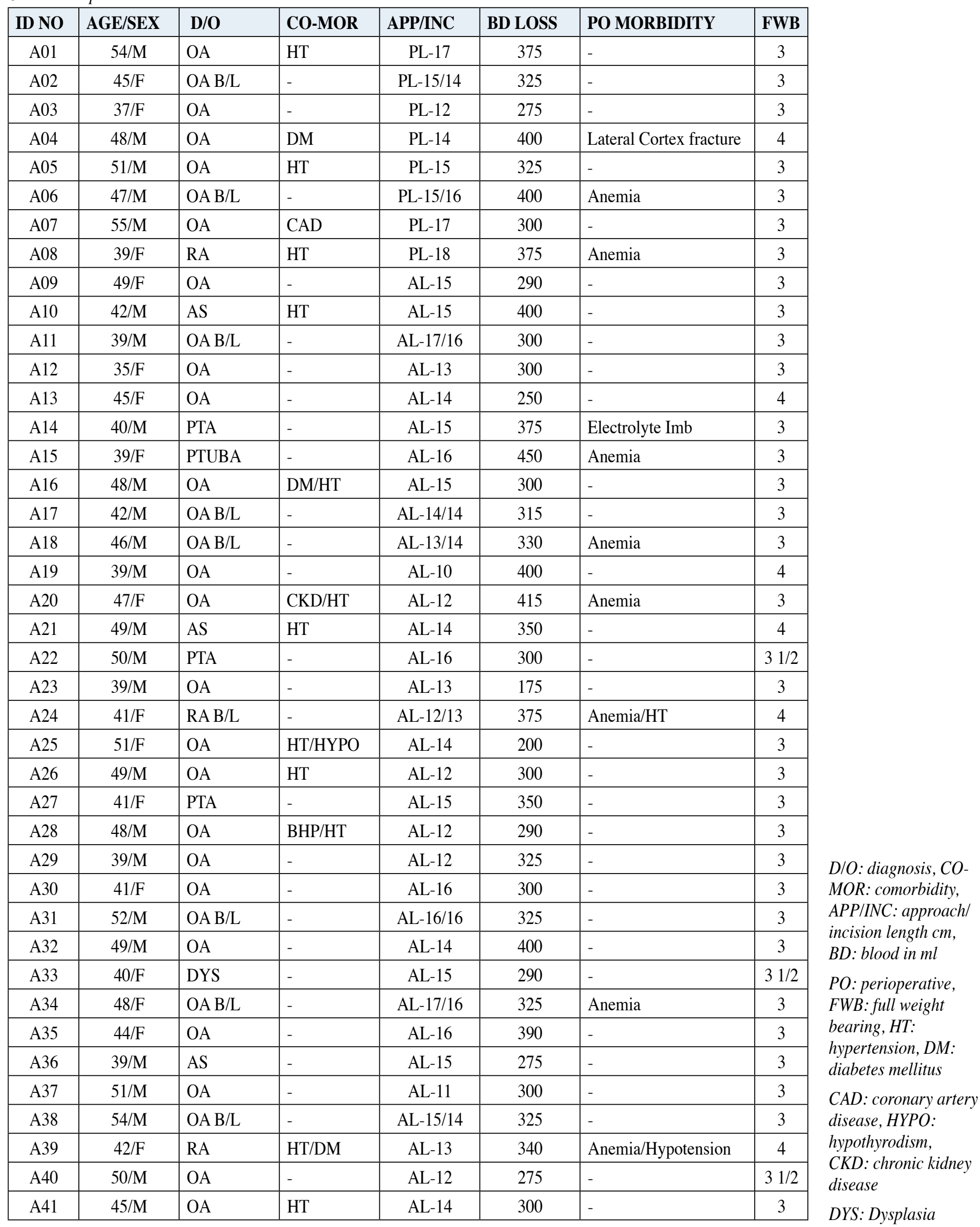


ter the hip was dislocated, the neck was osteotomised high at the base of head with full preservation of femoral neck. To prevent damage to greater trochanter-abductor complex and Gluteus medius muscle, a "Round the corner" technique had been used for broaching the femoral canal [1]. In this technique, the broaching and final implant insertion is done with a slight curved movement of the insertion handle. The broach is first introduced in varus position and then gradually bought to neutral position as broaching progresses. Specially designed broaches have been developed for this technique (Fig 1a and 1b). These broaches are anatomic and side specific. Alignment of the broach in the femur can be checked at any step by using an external alignment rod on the insertion handle. The definitive implant insertion is done in a similar fashion (Fig 2).

The femoral implant used was a Proxima metaphyseal stem (DePuy, USA) with either a large diameter metal on metal or Pinnacle metal on poly articulation (DePuy, USA).

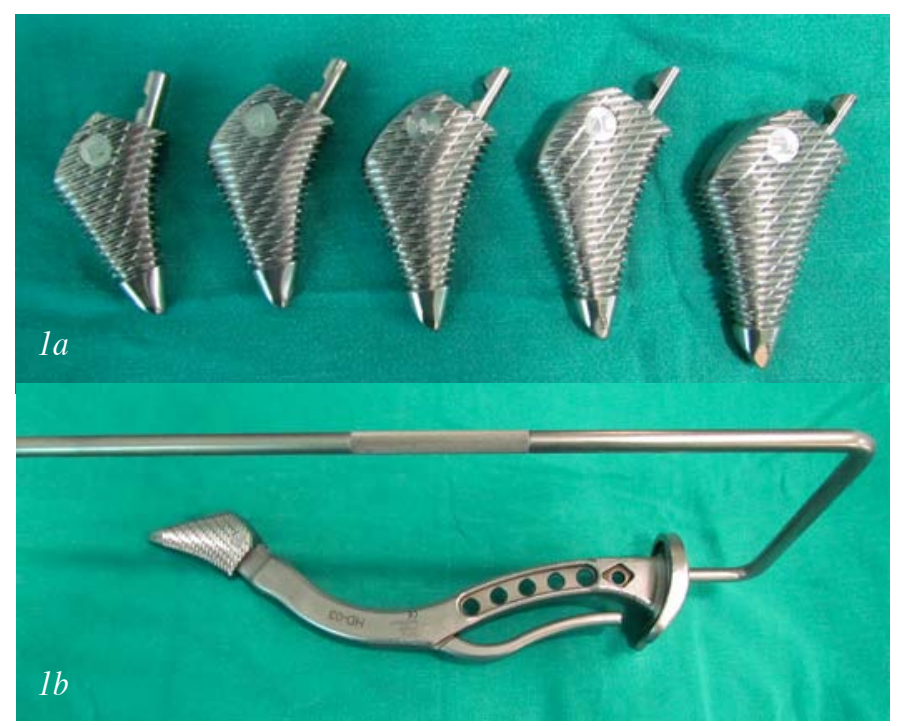

Figure $1 \mathrm{a}$ and $1 \mathrm{~b}$. Specially designed side specific broaches used for reaming the femur.

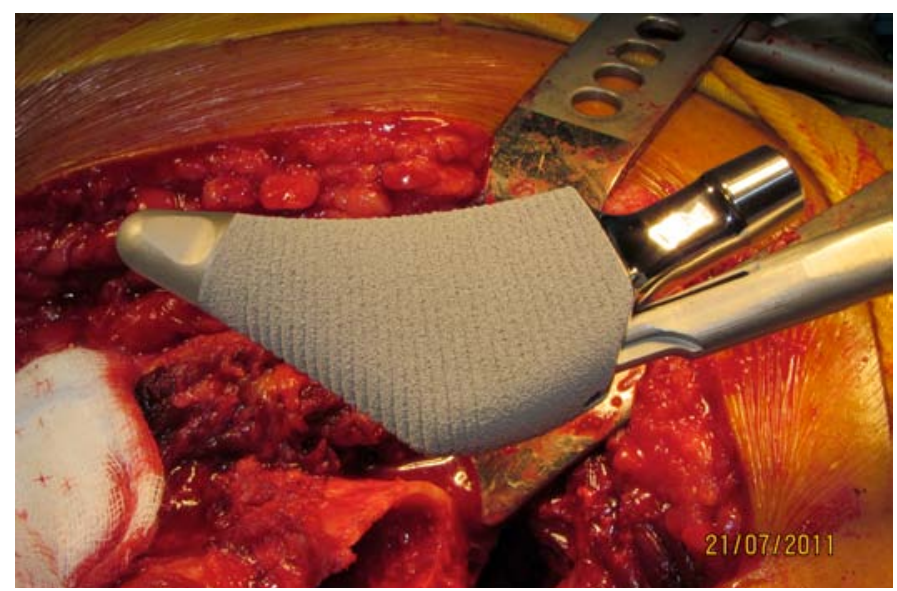

Figure 2. Intraoperative photo of proxima metaphyseal stem just before implantation
Postoperatively, all patients were kept in High Dependency Unit for one day for observation. Prophylactic intravenous antibiotics were used for 2 days and followed by oral antibiotics for another 5 days. On the 1st POD, routine blood investigations like haemogram and renal function were re-evaluated and blood was transfused if required. Suction drains were removed 24 hours after surgery and epidural catheters after 48 hours. All indwelt catheters were removed by 48 to 72 hours (after discontinuation of epidural anesthesia). All patients were kept on physical (foot and calf pumps) and chemical prophylaxis against DVT during their hospital stay.

Physiotherapy in the postoperative period involved static exercises in bed, side turning and bedside sitting on the first postoperative day. Mobilization with partial weight bearing with walker was started from the 2nd POD. Walker aided ambulation was continued for the next six weeks. Progression to full weight bearing and stick support was done gradually after six weeks following a clinical and radiological examination. Active hip mobilization, abductor and quadriceps strengthening exercises were continued. Supervised physiotherapy at home was usually continued for four to six weeks after surgery.

At three months, the ability of the patients to walk without support, squat and sit cross-legged was also assessed. If they satisfactorily performed these activities, they were allowed to progress to advanced activities such as swimming and golfing.

\section{Results}

The results were graded as excellent, good or poor on a simplified score based on parameters like VAS score, Harris hip score, return to normal and advanced hip function.

The first Proxima hip replacement was done by the senior author in July 2006. We report our experience with the first 50 such hip replacements using a Proxima metaphyseal stem on 41 patients. There were 25 males and 16 females in the study group. Nine of the 41 patients underwent bilateral hip replacement in a single sitting (Figure 3 ). The average age of the patient at the time of surgery was 45 years (range 35 to 55 years). The patients had a mean weight of 72 kgs. (Range 65 - 95 kgs.). 14 patients had associated co-morbidities like HT, DM, CAD and chronic kidney disease. The minimum duration of follow-up being 3 year. One patient was lost in the follow-up study period.

The implant used was a Proxima metaphyseal stem (DePuy, USA) with either a large diameter metal on metal XL or Pinnacle Metal on poly articulation (DePuy, USA). The first eight patients were operated through a posterio- 
Result Grading

\begin{tabular}{|c|c|c|c|c|c|c|}
\hline Grading & $\begin{array}{l}\text { Harris } \\
\text { Hip Score }\end{array}$ & $\begin{array}{l}\text { Retur } \\
\text { Basic }\end{array}$ & & $\begin{array}{l}\text { Retu } \\
\text { Adv }\end{array}$ & $\begin{array}{l}\text { Гo } \\
\text { d Hip }\end{array}$ & $\begin{array}{l}\text { Vas } 3 \\
\text { Mths }\end{array}$ \\
\hline Result & & & & & & \\
\hline & & $\begin{array}{l}\text { Unaid } \\
\text { Drivis }\end{array}$ & Car & Sittir & Light & \\
\hline & & Walki & & $\begin{array}{l}\text { Cros } \\
\text { Spor }\end{array}$ & gged & \\
\hline Excellent & 90 & Yes & Yes & Yes & Yes & $0-1$ \\
\hline Good & $80-90$ & Yes & No & Yes & No & 2 \\
\hline Poor & -80 & No & No & No & No & 3 \\
\hline
\end{tabular}

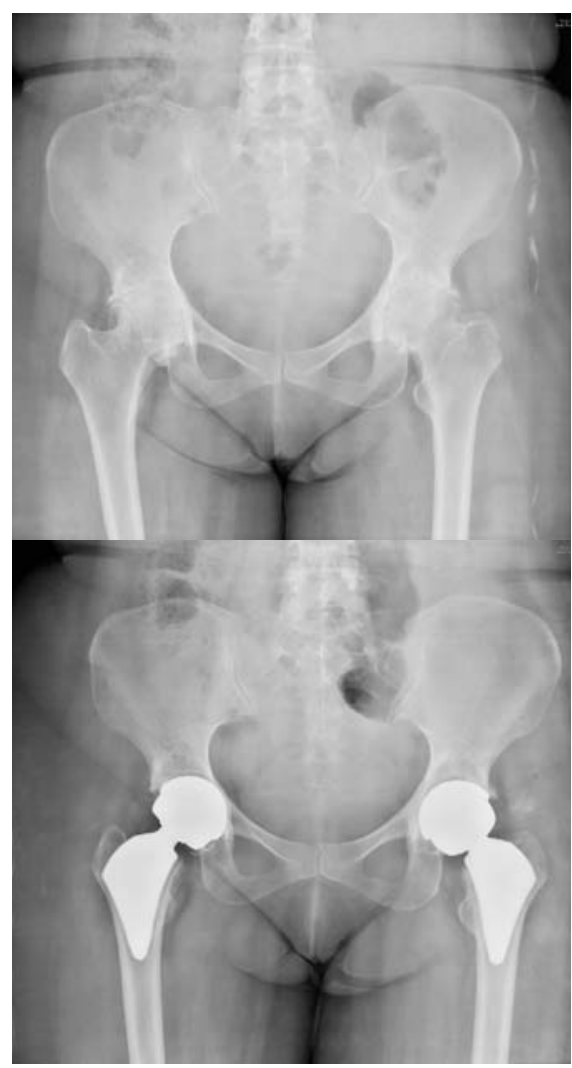

Figure 3. Preoperative and postoperative $x$-ray of a bilateral secondary hip osteoarthritis patient who underwent a bilateral hip replacement in the same sitting

lateral approach while remaining 33 were approached through an anterior-lateral approach. The incision size varied from $10 \mathrm{~cm}$ to $18 \mathrm{~cm}$ with an average of $14.38 \mathrm{~cm}$. The average post-operative blood loss for each hip was $269 \mathrm{ml}$ (range $175 \mathrm{ml}-450 \mathrm{ml}$ ). The mean Harris hip score before surgery was 52 (range 25-62), at 3 months was 75 , at one year was 85.8 at last follow up was 89.3 (range 86-91). The average VAS score at 3 months was 0.85 (0-3 range). All but 2 patients at three months follow-up achieved full weight bearing status without support. 39 of the 41 operated cases $(95.1 \%)$ showed excellent result at the last follow up with ability to walk without support, sit cross-legged, return to normal and advanced activities and had high satisfaction level with surgery.

\section{Result Chart}

\begin{tabular}{|c|c|c|c|c|c|}
\hline ID NO & $\begin{array}{c}\text { Follow } \\
\text { up }\end{array}$ & $\begin{array}{c}\text { VAS } \\
\text { (3 Mo.) }\end{array}$ & $\begin{array}{c}\text { Harris } \\
\text { Hip Score } \\
\text { (3 Mo.) }\end{array}$ & $\begin{array}{c}\text { Harris Hip } \\
\text { Score (12 } \\
\text { Mo.) } \\
\end{array}$ & $\begin{array}{l}\text { Harris Hip } \\
\text { Score (Last } \\
\text { Follow up) }\end{array}$ \\
\hline A01 & 49 & 2 & 74 & 84 & 89 \\
\hline A02 & 47 & 2 & 73 & 84 & 89 \\
\hline A03 & 56 & 0 & 80 & 89 & 91 \\
\hline A04 & 39 & 3 & 60 & 80 & 86 \\
\hline A05 & 45 & 1 & 68 & 77 & 88 \\
\hline A06 & 56 & 0 & 82 & 88 & 90 \\
\hline A07 & 57 & 2 & 69 & 81 & 88 \\
\hline A08 & 40 & 1 & 75 & 84 & 89 \\
\hline A09 & 36 & 1 & 79 & 85 & 89 \\
\hline $\mathrm{A} 10$ & 42 & 0 & 80 & 89 & 89 \\
\hline A11 & 47 & 3 & 75 & 64 & 89 \\
\hline A12 & 55 & 2 & 72 & 81 & 89 \\
\hline A13 & 60 & 1 & 80 & 88 & 90 \\
\hline A14 & 56 & 1 & 75 & 91 & 91 \\
\hline A15 & 44 & 0 & 80 & 89 & 90 \\
\hline A16 & 48 & 0 & 82 & 90 & 89 \\
\hline A17 & 57 & 1 & 80 & 90 & 90 \\
\hline A18 & 49 & 0 & 79 & 90 & 90 \\
\hline A19 & 40 & 1 & 69 & 88 & 89 \\
\hline A20 & 50 & 0 & 79 & 86 & 90 \\
\hline A21 & 37 & 0 & 82 & 89 & 91 \\
\hline $\mathrm{A} 22$ & 55 & 0 & 76 & 87 & 89 \\
\hline A23 & 49 & 3 & 73 & 84 & 88 \\
\hline A24 & 50 & 0 & 79 & 87 & 88 \\
\hline A25 & 44 & 0 & 76 & 86 & 89 \\
\hline A26 & 46 & 1 & 71 & 85 & 89 \\
\hline $\mathrm{A} 27$ & 50 & 0 & 77 & 88 & 90 \\
\hline A28 & 52 & 1 & 73 & 87 & 91 \\
\hline A29 & 59 & 2 & 70 & 82 & 90 \\
\hline $\mathrm{A} 30$ & 60 & 1 & 75 & 88 & 89 \\
\hline $\mathrm{A} 31$ & 48 & 0 & 79 & 89 & 90 \\
\hline A32 & 42 & 1 & 76 & 88 & 90 \\
\hline A33 & 38 & 1 & 78 & 89 & 89 \\
\hline $\mathrm{A} 34$ & 47 & 0 & 78 & 87 & 90 \\
\hline A35 & 40 & 1 & 72 & 84 & 89 \\
\hline A36 & 46 & 0 & 68 & 84 & 88 \\
\hline $\mathrm{A} 37$ & 38 & 2 & 69 & 86 & 89 \\
\hline A38 & 39 & 0 & 77 & 88 & 89 \\
\hline A39 & 45 & 0 & 75 & 86 & 90 \\
\hline $\mathrm{A} 40$ & 48 & 1 & 74 & 87 & 89 \\
\hline A41 & 40 & 0 & 78 & 90 & 90 \\
\hline
\end{tabular}

VAS: visual analogue score 
Five of our patients (12.1\%) in this study group had some sort of complications from which 3 recovered completly. These included undisplaced lateral cortex fracture, post-traumatic fracture of greater trochanter, superficial infection, femoral stem migration and aseptic stem loosening requiring stem revision.

The first patient had an intra-operative lateral cortex fracture that was only diagnosed on postoperative $\mathrm{x}$-rays. The femoral implant was otherwise in a good position. The patient was kept non-weight bearing with a walker for 6 weeks, sequential $x$-rays did not show any change in the stem positioning and then he was gradually allowed partial weight bearing. This patient made a satisfactory recovery.

The second patient developed pain around the hip about six weeks after surgery following a fall. X-rays showed an undisplaced fracture of the greater trochanter due to the fall. There was no displacement of the femoral prosthesis or acetabular component. He was treated conservatively with non-weight bearing and a hip abduction brace till the fracture healed fully on x-rays. However, he continued to have unexplained hip pain on walking. At one year, the pain continued to persist and he required stick support for walking. All investigations including repeated ESR, CRP, $\mathrm{X}$-rays and bone scan were normal. Hip joint aspirate yielded a negative culture report. In the absence of relief with conservative treatment, we advised the patient revision hip surgery for which he refused. This patient had poor satisfaction with surgery.

The third patient was operated for bilateral hip avascular necrosis and developed insidious onset of pain in one of the operated hips nine months after surgery. Investigations, including a Tc99 bone scan showed aseptic loosening of the femoral stem of the involved side. The acetabular cup had no evidence of loosening. Conservative treatment did not relieve him of symptoms, hence he was taken up for resurgery and the Proxima stem was revised to a fully coated uncemented stem (Corail, DePuy, USA) 12 months after his primary surgery. Intra-operatively the cup did not show any evidence of loosening and was retained. Moreover this patient has no symptoms on the contra-lateral Proxima hip. At 12 months follow-up after re-surgery, the patient was walking without support but with a slight limp (abductor lurch) and demonstrated good ability to sit on the floor. At 2-year follow-up he had a completely normal gait and was actively participating in exertional activities. At a recently concluded 5 year follow-up, he continues to be ok with no radiological evidence of femoral or acetabular change in both hips ( Fig 6).

The 4th patient developed stitch line discharge in the post-operative period. $\mathrm{C} / \mathrm{S}$ of the discharge showed staph. growth that was treated with appropriate injectable antibi- otics for 3 weeks. The discharge subsided and the patient made an uneventful recovery.

The last patient developed insidious femoral stem migration 3 years after the primary surgery. Investigations revealed aseptic loosening of stem for which she was advised revision surgery. We subsequently lost the patient in FU.

All 39 (95.1\%) other patients continue to be satisfied with their functional outcome and none showed radiological evidence of acetabular or femoral component loosening, osteolysis or migration at last follow-up. (Figure 4, Figure 5, Figure 6)

After the withdrawal of large diameter metal on metal articulation, all patients having metal on metal cups implanted were intimated of the withdrawal and evaluated with estimation of serum cobalt and chromium levels and

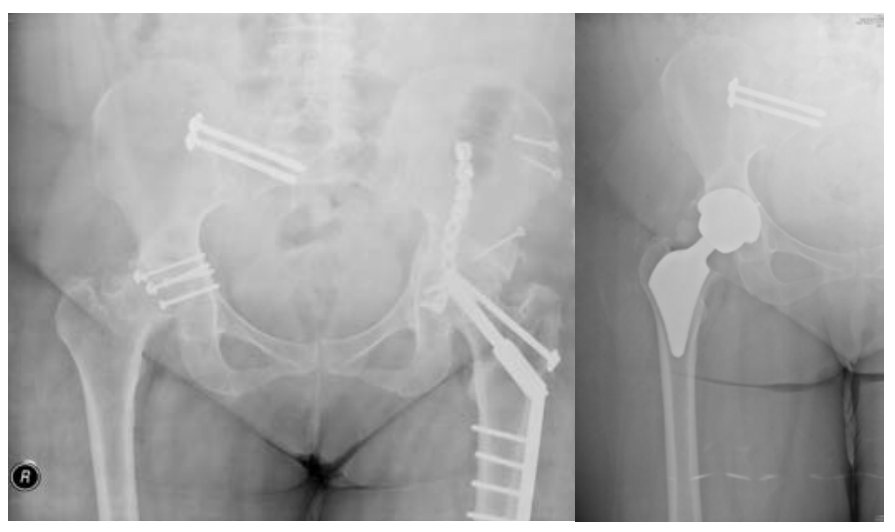

Figure 4. Preoperative and postoperative $x$-rays of a patient with post-traumatic hip osteoarthritis (right side operated).

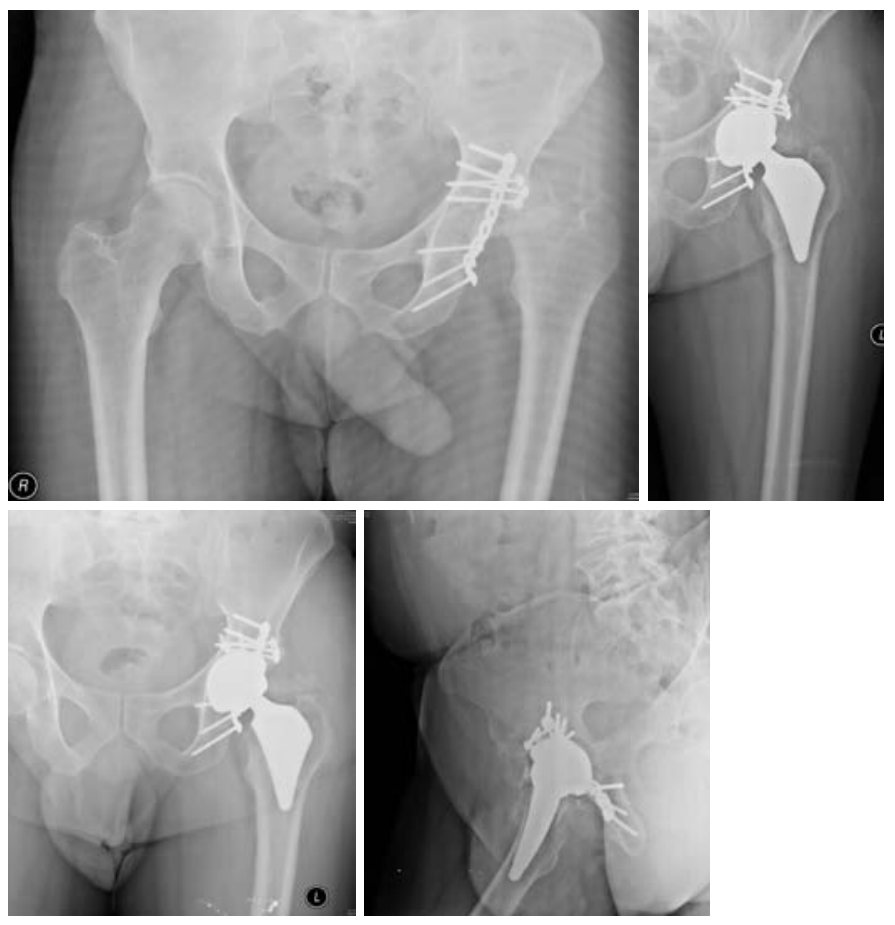

Figure 5. Preoperative and postoperative xrays of Proxima Replacement Following Fracture Acetabulum and $x$-rays after 1 year follow-up 

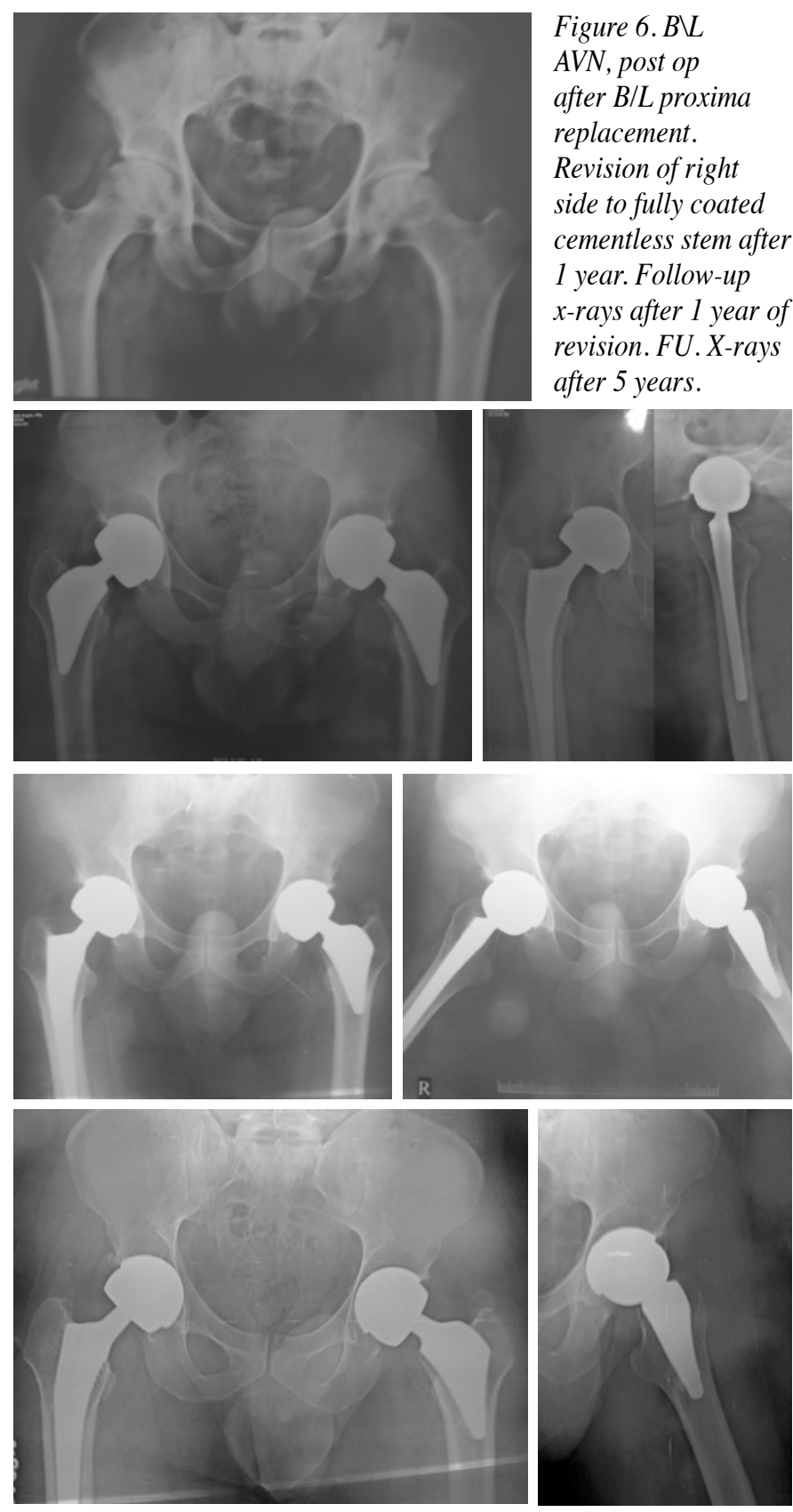

MARS (metal artifact reduction) MRI scan of the hip (as per recommendation of the manufacturers). Yearly evaluation of these patients is being done. None of the patients are symptomatic and at last follow-up, their investigation reports were normal. These patients will continue to be monitored as per recommendations.

\section{Discussion}

Cemented hip replacement has been documented to give good results particularly in elderly patients in terms of relief of pain and restoration of function. However their results in younger patients are far from ideal particularly in terms of stress shielding and revision surgery. [2]

In 1987, Jones and Hungerford [3] coined the term "cement disease" to describe cement induced osteolysis affecting cemented hip components. Although proved a misnomer, it added considerable interest in the swing towards cementless hip replacement.

Initially cementless implants showed considerable promise by providing stable fixation. But gradually a new set of problems emerged. Stable distal fixation and distal offloading resulted in stress shielding and loss of proximal femoral bone stock $[4,5]$. Kim et al [6] had published a report of 8.8 years follow-up that showed significant stress shielding at the calcar in a distal metaphyseal load-bearing stem. Thigh pain also emerged as a major issue and usually correlated to the stem length [7].

Despite significant advances in understanding of tribiology, better materials and improved fixation, these problems continued to plague cementless hips. In fact when considering the efficacy of porous coated cementless stems, Amstutz in 1991 noted "the incidence of thigh pain, radiological stress shielding and removal problems must still be solved....." [19].

Until recently, Resurfacing arthroplasty was the only technique available to surgeons for treatment of arthritis of the hip that preserved the femoral head. However even then, there were concerns regarding the vascularity of the remaining femoral head and incidence of femoral neck fractures after surgery. Also there were a set of well defined contraindications to resurfacing that limited its applications. Moreover, recent reports of increased metal ions in the blood and subsequent formation of pseudo-granulomas after their use has lead to the withdrawal of resurfacing prosthesis from the market.

The last 2 decades have shown a considerable change in the demographic profile of patients that are presenting for hip replacement surgery. Today's generation of patient demand much more from their replaced hips, particularly the ability to indulge in recreational activities and contact sports. Their hips are consequently exposed to considerably increased levels of stress. Hip implants thus need to be conservative with regards to bone and soft tissue insult, should be able to withstand the increased stresses placed upon them and last longer while making revision surgeries easier.

This fundamental shift towards the principle of reduced bone and soft tissue violation and the fact that an increased number of young patients are undergoing primary and revision hip surgery affords significant importance to bone preserving prosthesis.

In 1917, John C Koch [8] proposed his model of the 
mechanics of loading of the hip. In this model, he assigned compressive and tensile forces along the medial and lateral femoral surfaces. Fatto et al [9] further refined this model in 1995 and showed that the lateral femoral cortex can be effectively used to carry compressive loads. Leari et al [10] reviewed radiographs of primary THR with a lateral flare for axial migration and stability. They concluded that a prominent lateral flare provided significant initial stability through early bony ingrowth, which is vital for long term implant stability and provision against stress shielding. Interestingly, in 1993 Jasty et al [11] had proved that the diaphyseal portion of femoral stem is not required for implant stability once stable proximal fixation was achieved.

Thus in the absence of diaphyseal stem fixation, proximal load transfer through a anatomical lateral flare is an essential pre-requisite for best performance of an uncemented femoral stem in primary THR.

\section{Classification}

With so many short stems with significant variation in geometry and philosophy in the market, a simplified classification system was proposed by The Joint Implant Surgery and Research Foundation (JISRF). It basically classifies short stems under 4 groups [20].

1. Head Stabilized: now discontinued. It included
A. Hip Resurfacing
B. Mid-Head resection Stem

2. Neck Stabilized: a variety of neck stabilizing hip plugs, also called neck arthroplasty device by some surgeons, are now available. With minimal metaphyseal engagement, they are purely designed to sit in the femoral neck. This is one of the fastest growing market segments for short stems. Historically, femoral neck retention was advocated by Freeman, Townley, Whiteside and Pipino. Only Pipino advocated a short curved neck-sparing stem. The ring of cortical bone saved in the neck-sparing stem has significant bio-mechanical advantage. Pipino refered to this as a "tension band".
A. Short Curved Stems
B. Short Lateral Engaging Stem
C. Neck Plugs or Neck Only

3. Metaphyseal Stabilized: There is a long history of using short metaphyseal stems that include anatomical, straight, and tapered style stems. Variable results have been seen often depending on implant design, surgical technique, bone quality and patient related activities
A. Taper Stems
B. Bulky/Fit and Fill Stems

\section{Conventional Metaphyseal/Diaphyseal Stabilized}

Metaphyseal stems have been in use since 1978 when Huggler and Jacobs [12] designed the Thrust plate prosthesis (TPP). Buergi, Huggler and Ishaqui have all reported good to excellent mid term results with the Thrust plate prosthesis $[13,14,15]$. Early metaphseal stems like Mayo, Nanos and Metha stems represented the next generation of design based on the common principle of reduced femoral violation, non anatomic geometry, proximal calcar loading and lateral alignment in the presence of a shortened diaphyseal stem [16]. Radiological studies showed condensation of bone in the metaphyses and proximal diaphyses indicating early and stable biological fixation and the absence of stress shielding. Studies by various other authors have shown good to excellent results with these stems.

The IPS [17] (Immediate post operative stability) stem was a metaphseal filling anatomical stem launched in 1999 by DePuy. It had a distal diaphyseal extension used only for the purpose of stem alignment. It was designed to provide immediate post-operative stability within the proximal region of femur.

Based on the modified principle of femoral biomechanics by Fetto [9], F.S. Santori with his team at Stanmore customs designed and developed his custom metaphyseal stem in 1995, which he further modified in 1999 by entirely removing the distal stem. There were concerns that without distal fixation, the stem was susceptible to torsional strain, varus tilt and distal migration. However, as shown by Whiteside [18], a high neck cut prevents micromotion and provides rotational stability. The stem profile is anatomic and creates a wedging effect between proximal medial femur and lateral flare preventing distal stem migration. Santori has shown excellent clinical and radiological results and positive bone remodeling with this implant putting to rest the doubts raised about the functional efficacy of his implant [1].

Based on the principle of proximal load transfer and drawing its heritage from two previous uncemented stem, the IPS stem and Santori's custom stem, the proxima metaphyseal stem (DePuy, USA) was developed by an international team of surgeons.

Designed as a short uncemented, anatomic, metaphyseal stem, the Proxima stem was ideally poised to fulfill the demand for a conservative hip implant. It preserved the calcar area of the neck, maintained the integrity of the trochanteric area and attached abductor group of muscles and utilized the cancellous bone of the proximal femur to 
provide stable and durable biological fixation. With well defined medial and lateral trochanteric flares and absence of distal stem, it lend itself to minimally invasive surgery. This resulted in reduced soft tissue violation, less bone loss, accelerated rehabilitation and positive bone remodeling. Also due to its unique design features, it loaded the proximal femur most physiologically thus prevented stress shielding and increased available bone stock for future use.

Excellent studies by Santori, Learmonth and various other authors have shown that Proxima stem provided stable, predictable and durable biological fixation, reduced stress shielding and excellent remodeling $[1,17]$.

Another significant benefit expected from this short stem was in cases of revision surgery. It allowed for a conservative revision option in case of a failed conservative implant such as resurfacing prosthesis. Also in cases of its failure, as we have experienced, it could be easily revised and replaced with a traditional uncemented femoral stem with minimal bone loss [16].

\section{Conclusion}

In conclusion it can be expected that the future of hip stems may lie in a short anatomical stem that mimics the replaced femoral bone in every possible aspect, especially physiologically and biomechanically, minimizes violation of bony and soft tissue and provides for maximum available good quality bone stock for future use. Published results with this stem have been very encouraging and our own experience with this implant has strengthened this belief. Unfortunately, due to unknown reasons, the implant has been recently withdrawn from the market by DePuy and is no longer available for use. We shall however continue to follow all our operated cases in future, as we believe that this was the ideal implant for conservative hip surgeries and the future lies in this direction.

\section{Disclosure}

The authors declare that there is no conflict of interest regarding the publication of this paper. For full disclosures refer to last page of this journal.

\section{Referances:}

1. Santori FS, Manilim, Fredella N, Ottieri Tonci M, Santori N- ultra shot stem with proximal load transfer - Clinical \& radiological results at 5 years follow up. Hip international / volume 16, no 1(Suppl 3), 2006: s31-s39

2. Dorr LD, Kane TJ 3rd , Conaty JP. Long term results of cemented hip arthroplasty in patients 45 years old or younger. A 16 year followup study. J Arthroplasty 1995;10:255-6.

3. Jones LC, Hungerford DS. Cement disease. Clin Orthop 1987; 225(Dec):192- 206.

4. Engh CA, Bobyn JD, Glassman AH. Porous coated hip replacement. The factors governing bone ingrowth, stress shielding and clinical results. J Bone Joint Surg Br 1987; 69: 44-55.

5. Malchau H, Herberts P, Wang YX, Karlholm J, Romanus B. long term clinical and Radiological results of lord total hip prosthesis. A prospective study. J Bone Joint Surg Br 1986; 78: 884-91.

6. Kim YH. The results of a proximally coated cementless femoral component in total hip replacement: a five to 12 year follow-up. J Bone Joint Surg. 2008; 90-B: 299-305.

7. Vresilovic EJ, Hozack WJ, Rothman RH: incidence of thigh pain after uncemented total hip arthroplasty as a function of femoral stem size. J Arthroplasty 1996; 11: 304- 311 .

8. Koch JC: the laws of bone architecture. Am J Anat 1917; 21: 177 - 298.

9. Fetto JF, Bettinger P, Austin KS: re examination of hip biomechanics during unilateral stance Am J Orthop 1995; 8: 605 - 612.

10. Leali A, Fetto J, Insler H, Elfenbein D: the effect of a lateral flare feature on implant stability Int. Orthop 2002; 26: 166 - 169.

11. Jasty M, Krushell R, Zalenski E, O Connor D, Sedlacek R, Harris W (1993). the contribution of the non porous distal stem in the stability of proximally porous coated canine femoral components. J Arthroplasty 8 (1): $33-41$.

12. Huggler AH, Jacob HA. A new approach towards hip prosthesis design. Arch Orthop trauma Surg 1980; 97: $141-144$.

13. Buergi ML, Stoffel KK, Jacob HA, Bereiter HH. Radiological findings and clinical results of 102 Thrust plate femoral hip prosthesis. A follow-up of 2 to 8 years. J Arthroplasty 2005; 20:108-17.

14. Huggler AH, Jacob HA, Bereiter H, Haferkom M, Ryf C, Schenk R. Long term term results with uncemented thurst plate prosthesis. Acta Orthop Belg 1993; 59 ( supl 1): 215-23.

15. Ishaque BA, Weinbeck S, Struz H. Midterm results and revision of thurst plate prosthesis. Z Orthop Ihre Grenzgeb 2004; 142:25-32. 21

16. Falez F, Casella F, Panegroosi F, Favetti F, Barresi C. Perspective on metaphyseal conservative stems. J Orthop Traumatol 2008 March; 9(1):49-54.

17. Learmonth Ian D. Conservative hip implants. Current orthopedics (2005); 19:255262.

18. Whiteside LA, White SE, McCarthy DS (1995) effect of neck resection on torsional stability of cementless total hip replacement. Am J Orthop (10): 766 - 770

19. Amstutz HC, Namba R. Cementless femoral fixation using porous ingrowth fixation. In: Amstutz HC, editor. Hip arthroplasty. New York: Churchill Livingstone; 1991; p: 285-293.

20. McTighe T, Brazil D, Keggi JM, Keppler L, McPherson EJ. "Short-stem Designs for Total Hip Arthroplasty: Neck Stabilized Femoral Components" In book: The Adult Hip "Hip Arthroplasty Surgery" Third Edition, Chapter 64, Publisher: Wolters Kluwer, Editors: John J. Callaghan, Aaron G. Rosenberg, Harry E. Rubash, John C. Clohisy, Paul E. Beaule, Craig J. Della Valle, pp.823-849. 